\title{
Experiences of frontline nurses with adverse medical events in a regional referral hospital in northern Ghana: a cross-sectional study
}

\author{
Robert Kaba Alhassan ${ }^{1 *}$, Bilson Halilu², Saeed Mohammed Benin², Bentor Francis Donyor ${ }^{2}$, \\ Abubakar Yussuf Kuwaru², Dudu Yipaalanaa², Edward Nketiah-Amponsah³ ${ }^{3}$ Martin Amogre Ayanore ${ }^{4}$, \\ Aaron Asibi Abuosi ${ }^{5,5}$, Agani Afaya², Solomon Mohammed Salia² and Japiong Milipaak²
}

\begin{abstract}
Background: Adverse medical events (AMEs) are threats to delivery of quality healthcare services, particularly in resource-poor settings such as Ghana. In sub-Saharan Africa, 30\% of deaths are attributed to AMEs and a significant proportion of these events are not reported. This study explored personal experiences of nurses with AMEs and the constraints to reporting them.

Methods: This is a descriptive cross-sectional study among professional $(n=133)$ and auxiliary $(n=88)$ nurses in a regional referral hospital in northern Ghana. A test for differences in experiences of professional and auxiliary nurses was done using Wilcoxon Mann-Whitney test. Ordered logistic regression analysis (proportional odds ratio models) and probit regression were used to ascertain the determinants of staff's knowledge on AMEs and the odds of exposure, respectively.
\end{abstract}

Results: Overall, knowledge and awareness level on AMEs was average (mean $=3.1$ out of the five-point Likert scale of $1=$ "Very poor" to $5=$ "Excellent"). Knowledge levels among professional nurses (mean $=3.2)$ were relatively higher than those among auxiliary nurses (mean $=3.0)$, $(p=0.006)$. The predominant type of AME experienced was wrongful documentation $(n=144)$, and the least experienced type was wrong transfusion of blood and/or intravenous fluids (IVF) $(n=40)$. Male staff had higher odds of experiencing medical errors relative to female staff, $\mathrm{OR}=2.39$ (95\% confidence interval (CI), 1.34-4.26). Inadequate logistics was the most perceived cause of AMEs. Knowledge on types of AMEs was significantly associated with gender of the respondents, $\mathrm{OR}=1.76(95 \% \mathrm{Cl}, 1.05-2.94)$; moreover, male staff had higher odds of knowing AME post-exposure action than female staff, $\mathrm{OR}=1.75$ ( $95 \% \mathrm{Cl}, 1.04-2.93)$.

Conclusion: Knowledge levels of nursing staff on AMEs were generally low, and even though exposures were high they were not reported. There is the need to integrate AME modules into the pre-service and in-service training curricula for nurses to enhance their knowledge on AMEs; reporting registers for AMEs should be made available in clinical sites and staff incentives given to those who report AMEs. Lastly, protocols on AMEs should form part of the quality assurance value chain for health facilities to promote compliance.

Keywords: Adverse medical events, Professional nurses, Auxiliary nurses, Regional referral hospital, Northern Ghana

\footnotetext{
* Correspondence: arkabason@gmail.com; ralhassan@uhas.edu.gh

'Department of Public Health Nursing, School of Nursing and Midwifery,

University of Health and Allied Sciences, Ho, Ghana

Full list of author information is available at the end of the article
}

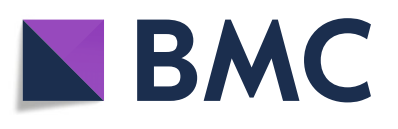

(c) The Author(s). 2019 Open Access This article is distributed under the terms of the Creative Commons Attribution 4.0 International License (http://creativecommons.org/licenses/by/4.0/), which permits unrestricted use, distribution, and reproduction in any medium, provided you give appropriate credit to the original author(s) and the source, provide a link to the Creative Commons license, and indicate if changes were made. The Creative Commons Public Domain Dedication waiver (http://creativecommons.org/publicdomain/zero/1.0/) applies to the data made available in this article, unless otherwise stated. 


\section{Background}

Adverse medical events (AMEs) are threats to delivery of quality healthcare services, particularly in resourcepoor settings such as Ghana. Adverse medical events are experienced by clinicians, including nurses, on a daily basis which include medication errors, adverse drug reaction, needlestick pricks, falls from a height or due to slippery floor, and transfusion reaction. Adverse medical events as used in this context include untoward events that directly or indirectly affect patients and healthcare staff. Studies have shown that even though healthcare workers suffer on a daily basis from these adverse events, the incidents are often not reported due to poor institutional reporting structures and limited knowledge of healthcare staff on these adverse medical events [1].

A review of the medical literature shows that staff experiences with adverse medical events were not given optimal attention by healthcare managers until the 1999 publication of "To Err is Human" by the United States (US) Institute of Medicine (IoM) [2]. This publication created the impetus for greater attention on this erstwhile neglected phenomenon in healthcare facilities. Since the release of the IoM report [2], many countries across the globe have voluntarily implemented adverse medical events reporting systems to promote safety of clients and healthcare providers. Nonetheless, as of December 2006, only 27 countries globally passed legislations, regulations, and executive orders for reporting adverse events in healthcare facilities [3].

Adverse medical events in clinical settings occur in developed and developing countries. For instance, medical errors are the third leading cause of death in the United States of America (USA) [4]. Moreover, the World Health Organization (WHO) [5] revealed that 23\% of European Union (EU) citizens claim they have been affected by medical errors and $50-70 \%$ of these medical errors were highly preventable.

Available statistics in Africa suggest worst trends on adverse medical events. In sub-Saharan Africa, it has been found that $30 \%$ of deaths are attributed to AMEs. A study by Ofori and Bates [6] showed that approximately 21\% AMEs were recorded in selected teaching hospitals in Ghana because of acute transfusion reaction [6].

AMEs get more challenging when they are not reported by clinical staff as observed by Gagliardi et al. [7] in their study among physicians, nurses, and other clinical staff in Canada and other countries [8,9]. A study by Alhassan and Poku [1] among 296 nurses and nurse assistants found that barely $44 \%$ of interviewed healthcare professionals reported their recent experience of an adverse event in the course of delivering health services.

In light of these low reporting trends among healthcare staff, Nwokike and Eghan [10] intimated that there is the need for a more comprehensive health safety system that goes beyond adverse events data collection to a greater emphasis on enforcement of better reporting systems that include evaluation, minimization, and communication of risks at every level of the healthcare system.

Notwithstanding the high incidence of AMEs in clinical settings, there is paucity of empirical literature on experiences of nurses, particularly in Ghana, resulting in a knowledge gap on this important health safety concern, particularly within the nursing profession. These observations necessitated this study which explored personal experiences of nurses with AMEs and the correlates of reporting trends among these clinical nurses. The study also examined constraints to reporting AMEs. It is expected that the findings of this study will help hospital managers, clinicians, and health policy makers develop robust reporting systems and enforce existing reporting policies on AMEs within the study setting and beyond.

\section{Methodology Study design/setting}

This is a descriptive cross-sectional study conducted among different cadres of nursing staff in a major regional referral hospital in the Upper West Region of Ghana.

The Upper West Region (UWR) is one of the administrative regions located in northern Ghana. The region shares boundaries with Burkina Faso to the north, Upper East region to the east, Ivory Coast to the west, and Northern region to the south. UWR covers a geographical area of approximately $18,478 \mathrm{~km}^{2}$ and constitutes about $12.7 \%$ of the total land area of Ghana; the region is located in the guinea savannah vegetation belt and has a population of 702,110 (341,182 males and 360,928 females) [11].

The study hospital is a major referral hospital for lower level hospitals within UWR, parts of Northern region and neighboring Burkina Faso. The hospital has a total bed capacity of 181 at the time of conducting this study. Services rendered in the facility include general medical services, ante-natal, post-natal, and maternal care. Other service components include specialist care such as ear nose and throat (ENT), dental, laboratory, and physiotherapy.

\section{Study population}

The study population included all cadres of nursing staff on permanent employment. The regional hospital has a total staff population of 682 at the time of conducting this study. Out of this number, 221 were paramedics, 114 casual workers, and 347 nurses of various categories (Upper West Regional: Hospital Administrative Records, 2018; unpublished). Thus, nursing personnel represented approximately $51 \%$ of the total workforce in the hospital. 


\section{Sample size and sampling technique}

The sampling technique was a census of all professional and auxiliary nurses across all the units of the hospital. Since the nursing staff population was 347, the entire population served as the target sample size $(n=347)$ for the study. However, three (3) extra questionnaires were printed to take care of instances where staff misplaced their questionnaire. This strategy was precautionary because not all questionnaires were retrieved on the day of visit due to busy schedules of some respondents.

\section{Inclusion/exclusion criteria}

The study included nurses of all categories such as professional and auxiliary nurses (i.e., staff licensed by the Nursing and Midwifery Council of Ghana). Only staff on permanent appointment were eligible for inclusion in the study. Also, staff who worked for at least six (6) months on the day of visit were included in this study to obtain data that is reflective of the true experiences of respondents. Staff on post-retirement contract, student nurses, or nurses on rotation/internship were equally excluded.

\section{Instruments of data collection}

A structured questionnaire, comprising of both closed and open-ended questions, was used for the data collection. Since all the target respondents were literates, the questionnaires were largely self-administered and later followed up by the researchers for retrieval. The data collection instrument comprised of four (4) main sections namely: section A (socio-demographic characteristics and work history), section $\mathrm{B}$ (experiences and exposure to AMEs), section $C$ (perspectives on causes of AMEs), and section D (reporting of AMEs). Some of the questions on experiences/exposure to AMEs were dichotomized into "Yes" and "No" while others were ranked on a four-point Likert scale as follows: 1 = "strongly disagree," 2 = "disagree," 3 = "agree," and 4 = "strongly agree." Questions on knowledge levels on AMEs were measured on a fivepoint Likert scale of 1 = "very poor," $2=$ "poor," 3 = "average," 4 = "good," and 5 = "excellent." All 22 Likert scale items were tested for scale reliability, and mean Cronbach's alpha was found to be 0.81 , which is acceptable.

\section{Reliability and validity}

The questionnaire was subjected to peer reviews and one pre-testing to promote its validity and reliability. The pre-testing did not lead to changes in the questionnaire, except correction of few typographical mistakes. Moreover, design of the questionnaire was guided by the research objectives and reviewed literature.

\section{Data analysis}

Data was analyzed using the STATA statistical analysis software (version 12.0, StataCorp, College Station, TX, USA). Field data was first captured with Microsoft Excel, cleaned and coded before exporting to STATA for analysis. Chi-square $\left(\chi^{2}\right)$ and Fisher's exact tests were used for the bivariate analysis of categorical data as appropriate while summary statistics on continuous variables were analyzed using independent Student's $t$ test. A test for differences between professional and auxiliary nurses on the Likert scale items was determined using Wilcoxon Mann-Whitney test.

Un-rotated factor analysis was conducted on the various Likert scale items to aggregate the various Likert scale items into similar components. Thus, seven items on staff knowledge on AMEs were factor-analyzed and three were retained, namely "types AMEs," "action(s) after AME experience," and "ability to recognize an incidence of AME." Questions on staff perspectives on the causes of AMEs were also factor-analyzed to arrive at five retained factors out of ten factors. The five retained factors were "poor communication," "inadequate staff," "poor management of previous AMEs," "inadequate skills on AMEs," and "inadequate motivation."

Finally, staff perspectives on barriers to reporting AMEs and the corresponding constraints were factoranalyzed and two factors retained out of five. The retained factors were "access to incidence report book" and "lack of clear reporting system."

\section{Outcome variables and covariates}

Following the factor analysis, ordered logistic regression analysis (proportional odds ratio models) was performed to ascertain determinants of the key outcome variables of interest. The main outcome variables of interest for the ordered logistic regression were the factor-analyzed proxies on knowledge, perceived causes, and constraints to reporting AMEs. Independent variables in the logistic regression were staff age $(18-30$ years $=1$, otherwise $=$ 0 ), education (first degree $=1$, otherwise $=0$ ), gender ( male $=1$, otherwise $=0)$, marital status $($ married $=1$, otherwise $=0$ ), religion (Christianity $=1$, otherwise $=0$ ), and work experience ( 5 years or less $=1$, otherwise $=0$ ). All independent variables were dichotomized to create uniform reference points (dummies) and enhance ease of interpretation of the findings.

Determinants of personal experience/exposure to AMEs were explored using probit regression. The main outcome variables were five factor-analyzed components on personal experiences with the various AMEs (yes $=1$, no $=0$ ). The five factor-analyzed components were needlestick pricks, equipment-related injuries, falls from slippery floor, medication errors, and falls from height. The independent variables in the probit regression are 
the same as those used for the logistic regression described earlier.

All independent variables were tested for multicollinearity prior to their inclusion in the regression models, and the mean variance inflation factor (VIF) was 1.26. None of the independent variables had a VIF above 10.0 necessary for exclusion from the regression models. Statistical significance was set at $95 \%$ for all analysis.

\section{Results}

\section{Socio-demographic features of respondents}

Over $60 \%$ of the respondents were aged 18-30 years. There was no statistically significant difference between professional and auxiliary nurses in terms of age; females dominated the study sample constituting 53\% while 63\% of the respondents said they were married. More professional nurses (37\%) said they were married than auxiliary nurses $(26 \%)(p=0.007)$. Christians constituted $51 \%$, and $62 \%$ of the respondents said they worked for 5 years or less (see Table 1).

Knowledge and experiences with adverse medical events A discretionary cut-off point for higher knowledge was a range of 4.01-5.00; average knowledge ranged from 3.014.00, and low knowledge was 2.01-1.00. Summated mean score for knowledge and awareness of AMEs was 3.1 out of the five-point scale. Knowledge levels among professional nurses was significantly higher (mean $=3.2$ ) than those among auxiliary nurses (mean $=3.0),(p=0.006)$. Respondents expressed better knowledge on "recognition of exposure to adverse medical events" (mean $=3.3$, SD = 1.0). It was found that professional nurses demonstrated better (mean $=3.4$, SD = 0.96) knowledge in "recognition of exposure to AMEs" than auxiliary nurses (mean = 3.1, $\mathrm{SD}=1.10), p=0.019$. On the whole, respondents were least informed in the area of "employer's role in preventing adverse medical events" (mean $=2.8, \mathrm{SD}=1.0)($ see Table 2$)$

Furthermore, it was discovered that the predominant AMEs experienced by the respondents were needlestick prick $(n=124)$, client reaction to transfusion $(n=115)$, wrongful documentation $(n=114)$, and transfusion reaction $(n=101)$. The least AMEs experienced were assault on the ward $(n=86)$, equipment-related injuries $(n=76)$, falls from slippery floors $(n=50)$ or height $(n=46)$, and wrongful transfusion $(n=40)$. In terms of proportions, more professional nurses (57\%) experienced wrongful documentation than auxiliary nurses (43\%), $p=0.001$; conversely, needlestick exposures were marginally higher among auxiliary nurses (58\%) than professional nurses (55\%), albeit the difference is not statistically significant. Likewise, more auxiliaries than professionals reported experience with transfusion reaction by clients, contact with client body fluids, and wrongful administration of
Table 1 Socio-demographic characteristics of respondents $(n=221)$

\begin{tabular}{|c|c|c|c|c|}
\hline \multirow{3}{*}{$\begin{array}{l}\text { Staff } \\
\text { characteristics }\end{array}$} & \multicolumn{4}{|c|}{ Professional category } \\
\hline & $\begin{array}{l}\text { Professional } \\
(n=133)\end{array}$ & $\begin{array}{l}\text { Auxiliary } \\
(n=88)\end{array}$ & $\begin{array}{l}\text { Total } \\
(n=221)\end{array}$ & $\begin{array}{l}p \\
\text { value }\end{array}$ \\
\hline & $f(\%)$ & $f(\%)$ & $f(\%)$ & \\
\hline \multicolumn{5}{|l|}{ Age } \\
\hline $18-30$ years & $87(39)$ & $58(26)$ & $145(66)$ & 0.170 \\
\hline $31-40$ years & $39(18)$ & 3014) & $69(31)$ & \\
\hline $41-50$ years & $5(2)$ & $0(0)$ & $5(2)$ & \\
\hline $51-60$ years & $2(1)$ & $0(0)$ & $2(1)$ & \\
\hline \multicolumn{5}{|l|}{ Gender } \\
\hline Male & $61(28)$ & $43(19)$ & $104(47)$ & 0.662 \\
\hline Female & $72(33)$ & $45(20)$ & $117(53)$ & \\
\hline \multicolumn{5}{|l|}{ Marital status } \\
\hline Married & $81(37)$ & $58(26)$ & $139(63)$ & 0.567 \\
\hline Not married & $52(24)$ & $30(14)$ & $82(37)$ & \\
\hline \multicolumn{5}{|l|}{ Religion } \\
\hline Christianity & $78(35)$ & $35(16)$ & $113(51)$ & $0.007^{*}$ \\
\hline Others & $55(25)$ & $53(24)$ & $108(49)$ & \\
\hline \multicolumn{5}{|l|}{ Work experience } \\
\hline 5 years or less & $81(37)$ & $55(25)$ & $136(62)$ & 0.811 \\
\hline Over 5 years & $52(24)$ & $33(15)$ & 85 (38) & \\
\hline
\end{tabular}

Source: field data (2018); legend: professional nurses (include registered general nurses, registered community health nurses, registered midwives and other professional post-basic specialist); auxiliary nurses (include nurse assistant clinical, nurse assistant preventive auxiliaries); $f$ (frequency)

*Fisher's exact

transfusion, but the differences were not statistically significant (see Fig. 1).

\section{Perceived causes of adverse medical events and reporting constraints}

Inadequate logistics in clinical settings was scored highest as the prime cause of adverse medical events (mean $=3.3 \pm 0.85)$. The least scored cause of adverse medical events was inadequate requisite skills of working staff (mean $=2.8 \pm 0.92)$. Other identified causes were improper management of previously reported AMEs, low staff motivation, inadequate number of staff, improper documentation, poor communication among staff, poor monitoring and supervision, and improper ward management (see Fig. 2).

Out of the 221 staff interviewed, 153 mentioned lack of mandatory reporting policy in their facility as the constraint to reporting AMEs; 140 staff mentioned lack of workplace support system as a constraint to reporting AMEs, more professional nurses (44\%) identified this as a constraint than auxiliary nurses $(56 \%)(p<0.05)$. Other constraints mentioned were available but inaccessible AME reporting book (139 out of 221), unavailability of 
Table 2 Knowledge on adverse medical events $(n=221)$

\begin{tabular}{|c|c|c|c|c|}
\hline \multirow{3}{*}{$\begin{array}{l}\text { Knowledge proxies on } \\
\text { AMEs }\end{array}$} & \multicolumn{4}{|c|}{ Professional category } \\
\hline & \multirow{2}{*}{$\begin{array}{l}\text { Professional } \\
(n=133) \\
\text { Mean } \\
(\mathrm{SD})^{* *}\end{array}$} & \multirow{2}{*}{$\begin{array}{l}\text { Auxiliary } \\
(n=88) \\
\text { Mean } \\
\text { (SD) }\end{array}$} & \multirow{2}{*}{$\begin{array}{l}\text { Total } \\
\text { Mean } \\
\text { (SD) }\end{array}$} & \multirow[t]{2}{*}{$p$ value } \\
\hline & & & & \\
\hline Types of AMEs & $3.3(0.97)$ & $3.1(1.10)$ & $3.2(1.00)$ & 0.0819 \\
\hline $\begin{array}{l}\text { Risk to exposure } \\
\text { to AMEs }\end{array}$ & $3.4(0.92)$ & $3.0(0.92)$ & $3.2(0.93)$ & $0.0055^{*}$ \\
\hline Advocacy on AMEs & $3.2(0.92)$ & $2.9(0.97)$ & $3.1(0.95)$ & $0.0190^{*}$ \\
\hline Reporting of AMEs & $3.2(0.99)$ & $3.2(1.10)$ & $3.2(1.00)$ & 0.7996 \\
\hline $\begin{array}{l}\text { Actions following } \\
\text { exposure to AMEs }\end{array}$ & $3.1(0.97)$ & $2.9(0.94)$ & $3.0(0.96)$ & 0.2201 \\
\hline $\begin{array}{l}\text { Employer's role } \\
\text { on AMEs }\end{array}$ & $3.0(1.00)$ & $2.8(1.10)$ & $2.9(1.00)$ & 0.0889 \\
\hline $\begin{array}{l}\text { Recognition of exposure } \\
\text { to AMEs }\end{array}$ & $3.4(0.96)$ & $3.1(1.10)$ & $3.3(1.00)$ & 0.0548 \\
\hline $\begin{array}{l}\text { Overall knowledge } \\
\text { score on AMEs }\end{array}$ & $3.2(0.70)$ & $3.0(0.70)$ & $3.1(0.71)$ & $0.0346^{*}$ \\
\hline
\end{tabular}

Source: field data (2018)

Legend:

*Wilcoxon Mann-Whitney two-tailed test of hypothesis at $95 \%$ confidence level

**Means and standard deviations derived from the summated 5-point Likert scale items on knowledge levels on AMEs from 1 "very poor" to 5 "excellent;" thus, higher mean scores depict better knowledge levels on AMEs and vice versa

AME reporting book (133 out of 221), and lack of clear reporting system for AMEs (113 out of 221) (see Fig. 3).

\section{Determinants of staff knowledge and exposure to AMEs}

It was discovered that knowledge on types of AMEs was significantly associated with gender of the respondents, OR $=1.76$ (95\% confidence interval $(\mathrm{CI}), 1.05-2.94)$; thus, being a male staff increased the odds of staff knowing the types of AMEs relative to females. Likewise, being a male staff improved the odds of knowing the post-AME exposure action than being a female, $\mathrm{OR}=1.75$ (95\% CI, 1.04-2.93). Overall, knowledge on all components of AMEs was correlated with being a male staff, OR = 1.97 (95\% CI, 1.19-3.25), and being a Christian by religion, $\mathrm{OR}=1.89$ (95\% CI, 1.17-3.05). Odds ratios were all adjusted for possible effect of confounding variables which were all controlled in the regression analysis. Significant covariates controlled in the regression model were respondents' age, gender, marital status, religion, and years of work experience. Factors such as professional category, staff age, years of work experience, and marital status did not seem to have a significant association with knowledge levels on AMEs (see Table 3).

In terms of the determinants of exposure to AMEs, it was found that male staff had higher odds of exposure to medical errors relative to female staff, OR $=2.39(95 \%$ CI, 1.34-4.26). Exposure to falls from slippery floor was found to be correlated with being a Christian relative to other religious faiths, $\mathrm{OR}=2.45$ (95\% CI, 1.22-4.90). Counter intuitively, professional category, gender, age, and years of work experience did not have a significant association with exposures such as needlestick pricks, equipment-related injuries, medication errors, and falls from heights (see Table 4).

\section{Discussion}

This study explored personal experiences of nurses in a major regional referral facility in the UWR of Ghana. In terms of staff self-rated knowledge levels on AMEs, it was found that the average rating was neither good nor excellent on any of the knowledge proxies. The least rated

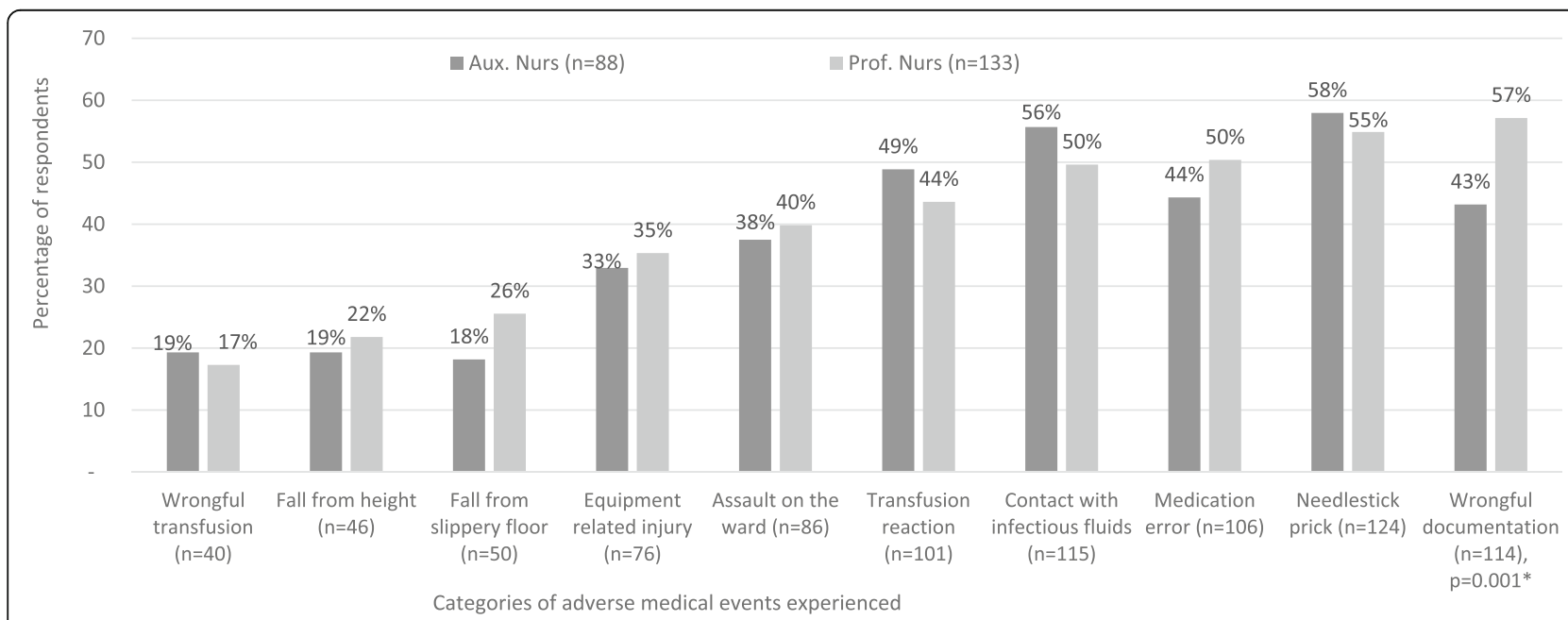

Fig. 1 Experiences with adverse medical events in the last 1 month $(n=221)$. Source: field data (2018); legend: Aux. Nurse (auxiliary nurses); Prof. Nurse (Professional nurse); $n$ (number of valid responses). Note: percentages are proportion of professional and auxiliary nurses who experienced each of the AMEs. The denominators as the total number of auxiliary $(n=88)$ and professional nurses $(n=133)$ respectively; *Fisher's exact test statistically significant at $95 \%$ confidence level. 


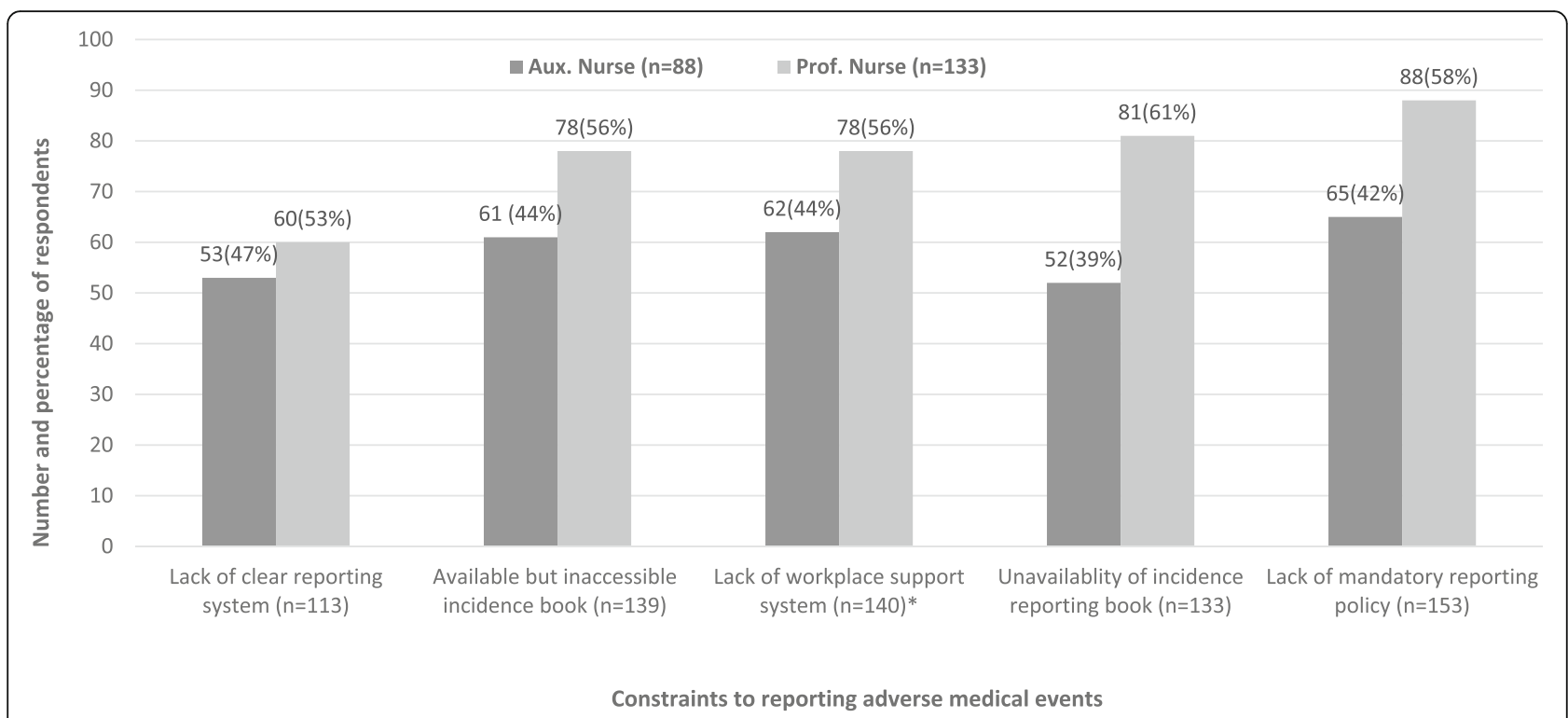

Fig. 2 Constraints to reporting adverse medical events ( $n=221$ ). Source: field data (2018); legend: Aux. Nurse (auxiliary nurses); Prof. Nurse (Professional nurse); $n$ (number of valid responses)

knowledge was on the role of employers in the control and prevention of AMEs. This observation corroborates previous studies on nurses' experiences with AMEs $[1,6$, 7]. Alhassan and Poku [1] and Gagliardi et al. [7] particularly found insufficient knowledge levels among nurses and physicians, respectively, on AMEs. Gagliardi et al. [7] further found significant differences between professional and auxiliary nurses on AMEs. Alhassan and Poku [1] observed that among the nursing staff, professional nurses demonstrated better knowledge on AMEs than their auxiliary colleagues. Perhaps the shorter and less detailed preservice training offered to auxiliary nurses [12] might account for these differences.

A systematic review involving 53 studies revealed that prevalence estimates for AMEs ranged from a low of $2 \%$ to a high of $94 \%$ [13]. It was found from this review that

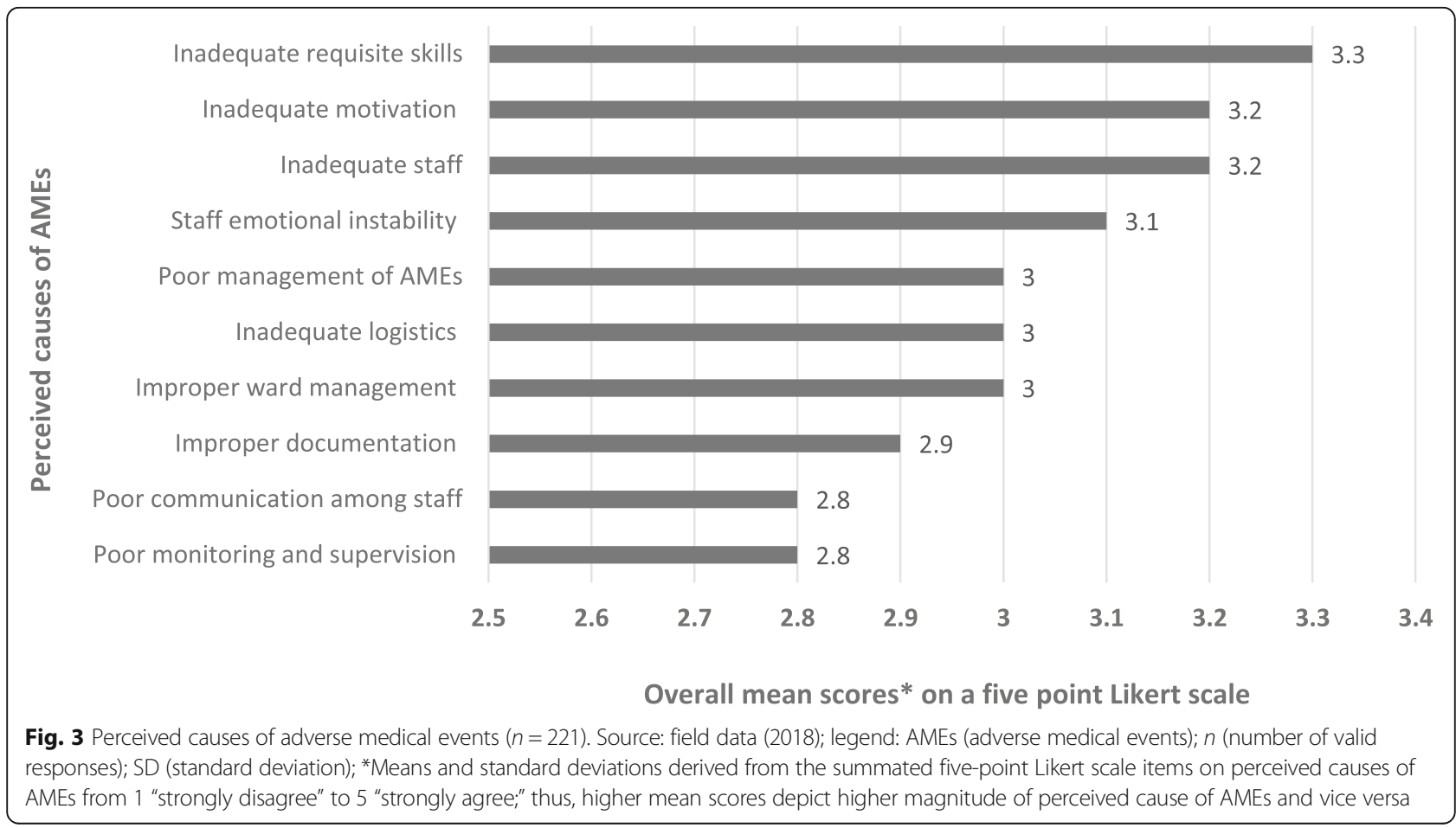


Table 3 Determinants of staff knowledge levels on adverse medical events ( $n=221$ )

\begin{tabular}{|c|c|c|c|c|}
\hline \multirow{3}{*}{$\begin{array}{l}\text { Independent } \\
\text { variables }\end{array}$} & Univariate model 1 & Univariate model 2 & Univariate model 3 & Univariate model 4 \\
\hline & Type of AMEs & Post exposure action & AMEs recognition & Overall knowledge \\
\hline & $\mathrm{OR}^{+}(95 \% \mathrm{Cl})$ & OR $(95 \% \mathrm{Cl})$ & OR $(95 \% \mathrm{Cl})$ & OR $(95 \% \mathrm{Cl})$ \\
\hline \multicolumn{5}{|l|}{ Professional category } \\
\hline Auxiliary nurse & $0.72(0.43-1.19)$ & $0.75(0.45-1.23)$ & $0.62(0.37-1.03)$ & $0.65(0.40-1.05)$ \\
\hline Professional nurse & Ref & Ref & Ref & Ref \\
\hline \multicolumn{5}{|l|}{ Age } \\
\hline $18-30$ years & $0.91(0.48-1.75)$ & $1.25(0.66-2.37)$ & $1.09(0.58-2.06)$ & $1.19(0.65-2.20)$ \\
\hline 31 years + & Ref & Ref & Ref & Ref \\
\hline \multicolumn{5}{|l|}{ Gender } \\
\hline Male & $1.76(1.05-2.94)^{*}$ & $1.75(1.04-2.93)^{*}$ & $1.46(0.87-2.44)$ & $1.97(1.19-3.25)^{*}$ \\
\hline Female & Ref & Ref & Ref & Ref \\
\hline \multicolumn{5}{|l|}{ Marital status } \\
\hline Married & $0.64(0.37-1.10)$ & $1.22(0.70-2.10)$ & $0.68(0.39-1.17)$ & $0.82(0.49-1.38)$ \\
\hline Not married & Ref & Ref & Ref & Ref \\
\hline \multicolumn{5}{|l|}{ Religion } \\
\hline Christian & $1.57(.96-2.60)$ & $1.42(0.86-2.32)$ & $1.13(0.68-1.88)$ & $1.89(1.17-3.06)^{*}$ \\
\hline Moslem & Ref & Ref & Ref & Ref \\
\hline \multicolumn{5}{|l|}{ Work experience } \\
\hline 5 years or less & $0.64(0.34-1.20)$ & $0.79(0.42-1.45)$ & $0.59(0.32-1.10)$ & $0.57(0.31-1.03)$ \\
\hline Over 5 years & Ref & Ref & Ref & Ref \\
\hline \multicolumn{5}{|l|}{ Model statistics } \\
\hline $\operatorname{LR} x^{2}(6)$ & 15.34 & 6.45 & 8.12 & 18.64 \\
\hline Prob $>x^{2}$ & 0.0090 & 0.2648 & 0.1500 & 0.0022 \\
\hline Pseudo $R^{2}$ & 0.0247 & 0.0107 & 0.0131 & 0.0145 \\
\hline Log likelihood & -302.24 & -298.52 & -305.66 & -635.37 \\
\hline
\end{tabular}

Source: field data (2018)

Legend: OR (odds ratio); $n$ (number of valid responses)

*ordered logistic regression significant, $p<0.05$

+Odds ratios (OR) are all adjusted for possible confounding covariates (i.e., age, gender, marital status, religion, and work experience)

inappropriate prescription was the predominant type of error reported. It was also found that the incidence of preventable adverse drug events (ADEs) for instance was estimated to be $15 / 1000$ person-years [13]. A similar review by Mekonenn et al. [14] confirmed the high prevalence of AMEs across the globe. However, many of these previous studies did not emphasize the experiences of healthcare professionals, particularly nurses who are either direct victims or contributing factors to patients' exposure to these AMEs [15].

In the African context, the numbers are even more overwhelming albeit there is limited empirical literature specifically reported on nurses [1]. In the reviewed literature, cases of AMEs are grossly underestimated since they are often unreported in deprived healthcare facilities due to a litany of reasons $[1,13,14]$ including inadequate knowledge on AMEs.

Respondents were also asked about their personal experiences with the different categories of AMEs. It was revealed that the predominant AME was needlestick pricks $(n=124)$ followed by wrongful documentation in the course of rendering care to clients $(n=114)$. The least AME exposure mentioned by the staff was wrong transfusion of blood and/or IVF. Other AMEs mentioned by the respondents were medication error, contact with infectious bodily fluids, transfusion reaction, assault on the ward, equipment-related injuries, and falls. This observation corroborates findings in previous publications where similar AMEs were reported in clinical settings in Ghana [1, 16-18] and other countries [13, 15, 19, 20].

It was also found that auxiliary nurses suffered more of needlestick pricks, contact with infectious bodily fluids, and wrong transfusion. Professional nurses on the other hand experienced more of wrongful documentation, medication error, assault on the ward, equipment-related injuries, and falls. Even though there is no much relevant empirical literature to compare with these current findings, Alhassan and Poku [1] observed similar dynamics in 
Table 4 Determinants of exposure to adverse medical events $(n=221)$

\begin{tabular}{|c|c|c|c|c|c|c|}
\hline \multirow[t]{3}{*}{$\begin{array}{l}\text { Independent } \\
\text { variables }\end{array}$} & $\begin{array}{l}\text { Univariate model } \\
1\end{array}$ & $\begin{array}{l}\text { Univariate model } \\
2\end{array}$ & Univariate model 3 & $\begin{array}{l}\text { Univariate model } \\
4\end{array}$ & $\begin{array}{l}\text { Univariate model } \\
5\end{array}$ & $\begin{array}{l}\text { Univariate model } \\
6\end{array}$ \\
\hline & Need pricks & Equipment injuries & $\begin{array}{l}\text { Falls from slippery } \\
\text { floors }\end{array}$ & Medication errors & Falls from height & Overall exposure \\
\hline & $\mathrm{OR}^{+}(95 \% \mathrm{Cl})$ & OR (95\% Cl) & OR $(95 \% \mathrm{Cl})$ & OR $(95 \% \mathrm{Cl})$ & OR $(95 \% \mathrm{Cl})$ & OR (95\% Cl) \\
\hline \multicolumn{7}{|c|}{ Professional category } \\
\hline Auxiliary nurse & $1.28(0.72-2.25)$ & $0.96(0.53-1.72)$ & $0.75(0.37-1.50)$ & $0.68(0.38-1.21)$ & 0.87 (0.44 1.74) & 1.03 (0.09 12.52) \\
\hline $\begin{array}{l}\text { Professional } \\
\text { nurse }\end{array}$ & Ref & Ref & Ref & Ref & Ref & Ref \\
\hline \multicolumn{7}{|l|}{ Age } \\
\hline 18-30 years & $0.57(0.28-1.18)$ & $0.89(0.421 .87)$ & $0.67(0.27-1.65)$ & $0.72(0.34-1.51)$ & $1.52(0.633 .70)$ & 0.61 (0.02 19.23) \\
\hline 31 yearst & Ref & Ref & Ref & Ref & Ref & Ref \\
\hline \multicolumn{7}{|l|}{ Gender } \\
\hline Male & $1.00(0.57-1.77)$ & $1.274(0.71-2.29)$ & $1.10(0.56-2.18)$ & $2.39(1.34-4.26)^{*}$ & 0.79 (0.39 1.58) & 0.74 (0.06 9.13) \\
\hline Female & Ref & Ref & Ref & Ref & Ref & Ref \\
\hline \multicolumn{7}{|l|}{ Marital status } \\
\hline Married & $0.74(0.40-1.37)$ & $1.04(0.56-1.96)$ & $0.81(0.39-1.65)$ & $1.24(0.67-2.31)$ & 1.04 (0.50 2.18) & 1.35 (0.10 18.65) \\
\hline Not married & Ref & Ref & Ref & Ref & Ref & Ref \\
\hline \multicolumn{7}{|l|}{ Religion } \\
\hline Christian & $1.74(0.99-3.05)$ & $1.46(0.82-2.61)$ & $2.45(1.22-4.90)^{*}$ & $0.68(0.39-1.20)$ & $1.08(0.552 .13)$ & omitted $^{* *}$ \\
\hline Moslem & Ref & Ref & Ref & Ref & Ref & Ref \\
\hline \multicolumn{7}{|l|}{ Work experience } \\
\hline 5 years or less & $1.66(0.83-3.35)$ & $9.91(0.45-1.87)$ & $1.93(0.80-4.68)$ & $1.86(0.91-3.82)$ & $0.88(0.38$ 2.02) & $1.80(0.0654 .08)$ \\
\hline Over 5 years & Ref & Ref & Ref & Ref & Ref & Ref \\
\hline \multicolumn{7}{|l|}{ Model statistics } \\
\hline $\operatorname{LR} x^{2}(6)$ & 7.78 & 2.54 & 11.36 & 17.04 & 1.99 & 0.24 \\
\hline Prob $>x^{2}$ & 0.2546 & 0.8639 & 0.0778 & 0.0091 & 0.9204 & 0.9987 \\
\hline Pseudo $R^{2}$ & 0.0257 & 0.0089 & 0.0481 & 0.0557 & 0.0088 & 0.0086 \\
\hline Log likelihood & -147.64 & -140.96 & -112.49 & -144.48 & -112.04 & -13.73 \\
\hline
\end{tabular}

Source: field data (2018)

Legend: OR (odds ratio)

* logistic regression statistically significant, $p<0.05$

**omitted variable from regression model due to collinearity

+Odds ratios (OR) are all adjusted for possible confounding covariates (i.e., age, gender, marital status, religion, and work experience)

the exposure of professional and auxiliary nurses in two psychiatric hospitals in Ghana.

These observations could be attributed to the differences in training and work mandate of these different cadres of nurses in Ghana. For instance, the relatively higher exposure of professional nurses to documentation, medication errors, and equipment-related injuries could be because these nursing duties are predominantly within the mandate of professional nurses and this could increase the odds of their exposure because they often perform these duties.

Conversely, the higher exposure of auxiliary nurses to transfusion reaction and administration of wrong transfusions could be attributed to instances when these duties are performed on behalf of professional nurses in the form of task shifting due to limited number of qualified professional nurses in Ghana, like many countries in Africa [12,
21, 22]. This phenomenon perhaps reflects the spillover effects of acute shortage of professional nurses in predominantly rural regions in northern Ghana which continue to record lower staff to patient ratios below the national averages [22]. The differences in self-reported exposures by the professional and auxiliary nurses might be attributed to differences in the honesty of staff in reporting these AMEs especially when evidence of professional negligence is implied as argued by Edwin [18] in his study on nondisclosure of medical errors in Ghana.

On the perceived causes of AMEs, inadequate logistics was rated highest while the least perceived cause was staff emotional instability. Other perceived causes were inadequate staff numbers, poor monitoring and supervision, inadequate skills of staff, improper ward management, poor staff motivation, unsatisfactory management of previous 
AMEs, poor communication among staff, and improper documentation. These responses support similar conclusions on causes of AMEs in Ghana $[1,16,17,23]$ and other countries $[13,15,19,20]$. The responses re-echo the longstanding challenges of most developing health systems in Africa, ranging from human and material resource constraints. The effects of these health system challenges on the safety of staff and clients have been confirmed in this study and similar studies in the past $[1,5,13,15,24]$.

In terms of the constraints to reporting exposures to AMEs, majority of the respondents mentioned the absence of a mandatory reporting policy for AMEs. Lack of workplace support system and inaccessible AME reporting books/registers were also identified as major constraints to reporting AMEs. Alhassan and Poku [1] observed in their study among 296 nurses and nurse-assistants in Ghana that majority of nurses did not report AMEs because of unclear reporting system, poor management of previous exposures leading to loss of trust and confidence in facility heads. Similar conclusions were made in previous studies that investigated barriers to reporting AMEs in healthcare facilities $[5,13,15,16,18,23]$.

Finally, after controlling for relevant covariates, it was found that gender significantly predicted higher odds of staff knowledge on AMEs and exposure to medication errors. Mrayyan et al. [25] made similar observation in their study on predictors of reporting medication errors in Jordan where gender emerged as a significant correlate. However, Alhassan and Poku [1] in their study on workplace safety among nursing staff in psychiatric hospitals in Ghana did not find statistically significant association between gender and exposure to AMEs. Perhaps the gender effect in this current study could be explained by the fact this study was not conducted in psychiatric facilities as the case in Alhassan and Poku [1]. Moreover, like many countries, the nursing profession in Ghana is female dominated, and since a greater proportion of the professional nurses were females who had lower tendency of committing medication error, the study is not counterfactual in demonstrating that more males had higher odds of experiencing medication errors relative to their female colleagues.

\section{Conclusion}

Overall, this study found that even though nurses experienced AMEs on a daily basis, the victims of these AMEs did not have adequate knowledge in terms of the types, reporting, steps to be taken after exposure, and the role of their employer in AMEs control and prevention. The study also revealed that professional and auxiliary nurses do not experience equal proportions of the different types of AMEs. Thus, some AMEs were more common with professional nurses than with auxiliary nurses. Perceived causes of AMEs were however almost uniformly enumerated by the staff which include inadequate material and human resources, poor monitoring and supervision, and improper ward management and documentation. Staff generally identified lack of mandatory reporting policy for AMEs, inaccessibility of AMEs reporting registers, lack of workplace support, and unclear reporting system as key constraints to reporting AMEs.

\section{Implications for nursing policy and clinical practice}

In light of the above findings, the following policy recommendations are proposed to promote safety of nurses and clients:

1. Pre-service and in-service training curricula for nurses should incorporate detailed modules on AMEs to adequately prepare them ahead of clinical practice. In line with this, protocols for reporting AMEs and registers for reporting AMEs should also be made available and clearly communicated to staff to ensure compliance

2. Incentive packages should also be introduced to reward staff who routinely report incidence of AMEs to promote compliance

3. As part of accreditation processes for healthcare facilities, protocols for monitoring and preventing AMEs should form part of the mandatory requirements for passing the accreditation to encourage compliance by health facilities

\section{Limitations of the study}

This study is based on perceptions of nurses on AMEs. Findings may therefore be different from the reality in practice. In view of this, future studies could review patient medical records retrospectively to ascertain veracity or otherwise of findings of this study.

\section{Abbreviations}

ADEs: Adverse drug events; AMEs: Adverse medical events; EU: European Union; IOM: Institute of Medicine; IVF: Intravenous fluid; USA: United States of America; UWR: Upper West Region; VIF: Variance inflation factor; WHO: World Health Organization

\section{Acknowledgements \\ The authors acknowledge the support and cooperation of the staff of the Upper West regional hospital particularly those who volunteered to participate in this study. The managers and administrators of various units of the hospital are also duly recognized for their support to conduct this study. Finally, we appreciate colleague researchers who helped in the data collection and internal peer review processes}

\section{Authors' contributions}

$\mathrm{BH}, \mathrm{SMB}, \mathrm{BFD}, \mathrm{AYK}$, and DY initiated the conceptualization and writing of the paper. BH, SMB, BFD, AYK, and DY collected, entered, and cleaned the field data. RKA and EN-A provided advice on the analysis and the interpretation of the results. RKA, EN-A MAA, AAA, SMS, JM, and AA reviewed the manuscript and provided relevant expert advice. All authors read and approved the final manuscript.

Funding

There was no funding for this study. 


\section{Availability of data and materials}

All data supporting our findings are contained in the manuscript. There are no restrictions to data and datasets are available from the corresponding author upon reasonable request.

\section{Ethics approval and consent to participate}

Ethical clearance was obtained from the Research and Ethics Committee (REC) of the University of Health and Allied Sciences (clearance number: UHASRECA.2[23]18-19). Written informed consent was additionally obtained from the respondents prior to the survey. Moreover, administrative approval was sought from the Upper West Regional Health Directorate as well as the hospital administration. Anonymity and confidentiality of the participants were maintained throughout this study by coding the field data.

\section{Consent for publication}

Not applicable.

\section{Competing interests}

The authors declare that they have no competing interests.

\section{Author details}

'Department of Public Health Nursing, School of Nursing and Midwifery, University of Health and Allied Sciences, Ho, Ghana. ${ }^{2}$ School of Nursing and Midwifery, University of Health and Allied Sciences, Ho, Ghana. ${ }^{3}$ Department of Economics, University of Ghana, Legon, Ghana. ${ }^{4}$ School of Public Health, University of Health and Allied Sciences, Hohoe, Ghana. ${ }^{5}$ Department of Health Services Management and Public Administration, University of Ghana Business, University of Ghana, Legon, Ghana.

Received: 14 February 2019 Accepted: 13 May 2019

Published online: 28 May 2019

\section{References}

1. Alhassan RK, Poku KA. Experiences of frontline nursing staff on workplace safety and occupational health hazards in two psychiatric hospitals in Ghana. BMC Public Health. 2018;18(1):701.

2. Kohn LT, Corrigan JM, Donaldson MS. To err is human: building a safer health system. A report of the Committee on Quality of Health Care in America, Institute of Medicine (IOM); 2000.

3. Hess C, Schwartz C, Rosenthal J, Snyder A, Weil A. State health policies aimed at promoting excellent systems: a report on states' roles in health systems performance, National Academy for State Health Policy (NASHP), Washington, D. C USA; 2008.

4. Makary MA, Daniel M. Medical error-the third leading cause of death in the US. Bmj. 2016;353:i2139.

5. World Health Organization (WHO). Patient safety, data and statistics. Geneva: World Health Organization (WHO); 2017.

6. Owusu-Ofori AK, Owusu-Ofori SP, Bates I. Detection of adverse events of transfusion in a teaching hospital in Ghana. Transfus Med. 2017;27(3):175-80.

7. Gagliardi AR, Ducey A, Lehoux P, Turgeon T, Ross S, Trbovich P, Easty A, Bell C, Urbach D. Factors influencing the reporting of adverse medical device events: qualitative interviews with physicians about higher risk implantable devices. BMJ Qual Saf. 2018;27(3):190-8.

8. Kable A, Kelly B, Adams J. Effects of adverse events in health care on acute care nurses in an Australian context: a qualitative study. Nurs Health Sci. 2018 Jun;20(2):238-46

9. Leape LL. The preventability of medical injury. In Human error in medicine (pp. 13-25). Borca Raton, CRC Press; 2018. eBook ISBN 9780203751725.

10. Nwokike J, Eghan K. Pharmacovigilance in Ghana: a systems analysis. Submitted to the U.S. Agency for International Development by the Strengthening Pharmaceutical Systems (SPS) Program. Arlington: Management Sciences for Health; 2010.

11. Ghana Statistical Service (GSS). 2010 population and housing census: summary report of final results. Accra: GSS Accra; 2012.

12. Ghana Health Workers Observatory (GHWO). Human resources for health: country profile Ghana. Accra; 2011.

13. Assiri GA, Shebl NA, Mahmoud MA, Aloudah N, Grant E, Aljadhey H, Sheikh A. What is the epidemiology of medication errors, error-related adverse events and risk factors for errors in adults managed in community care contexts? A systematic review of the international literature. BMJ Open. 2018;8(5):e019101.
14. Mekonnen AB, Alhawassi TM, McLachlan AJ, Jo-anne EB. Adverse drug events and medication errors in African hospitals: a systematic review. Drugs Real World Outcomes. 2018;5(1):1-24.

15. Mercer S, Furler J, Moffat K, Fischbacher-Smith D, Sanci L. Multimorbidity: technical series on safer primary care. Geneva: World Health Organization; 2016.

16. Acheampong F, Tetteh AR, Anto BP. Medication administration errors in an adult emergency department of a tertiary health care facility in Ghana. $J$ Patient Saf. 2016;12(4):223-8.

17. Koffuor GA, Anto BP, Abaitey AK. Error-provoking conditions in the medication use process: the case of a government hospital in Ghana. J Patient Saf. 2012;8(1):22-5.

18. Edwin AK. Non-disclosure of medical errors an egregious violation of ethical principles. Ghana Med J. 2009;43(1):34.

19. Holloway KA, Ivanovska V, Wagner AK, Vialle-Valentin C, Ross-Degnan D. Have we improved use of medicines in developing and transitional countries and do we know how to? Two decades of evidence. Tropical Med Int Health. 2013;18(6):656-64.

20. Yin HS, Dreyer BP, Moreira HA, van Schaick L, Rodriguez L, Boettger $S$, Mendelsohn AL. Liquid medication dosing errors in children: role of provider counseling strategies. Acad Pediatr. 2014;14(3):262-70.

21. Ministry of Health $(\mathrm{MoH})$. Wholistic assessment of the health sector. Accra: $\mathrm{MoH} ; 2015$

22. Ghana Health Service (GHS). Annual report. Accra: Ministry of Health/Ghana Health Service; 2017.

23. Acheampong F, Anto BP. Perceived barriers to pharmacist engagement in adverse drug event prevention activities in Ghana using semi-structured interview. BMC Health Serv Res. 2015;15(1):361.

24. Rowe AK, Labadie G, Jackson D, Vivas-Torrealba C, Simon J. Improving health worker performance: an ongoing challenge for meeting the sustainable development goals. BMJ. 2018;362:k2813.

25. Mrayyan MT, Shishani K, AL-FAOURI IB. Rate, causes and reporting of medication errors in Jordan: nurses' perspectives. J Nurs Manag. 2007:15(6):659-70.

\section{Publisher's Note}

Springer Nature remains neutral with regard to jurisdictional claims in published maps and institutional affiliations.
Ready to submit your research? Choose BMC and benefit from:

- fast, convenient online submission

- thorough peer review by experienced researchers in your field

- rapid publication on acceptance

- support for research data, including large and complex data types

- gold Open Access which fosters wider collaboration and increased citations

- maximum visibility for your research: over $100 \mathrm{M}$ website views per year

At $\mathrm{BMC}$, research is always in progress.

Learn more biomedcentral.com/submissions 